\title{
Knowledge and attitudes of dentists regarding the treatment of renal transplant patients
}

- Rubens Caliento Special Care Dentistry Center, Department of Stomatology, School of Dentistry, University of São Paulo, São Paulo, Brazil - Patrícia P. Shibutani Special Care Dentistry Center, Department of Stomatology, School of Dentistry, University of São Paulo, São Paulo, Brazil • Amábile O. Souza Special Care Dentistry Center, Department of Stomatology, School of Dentistry, University of São Paulo, São Paulo, Brazil • Marina Gallottini Special Care Dentistry Center, Department of Stomatology, School of Dentistry, University of São Paulo, São Paulo, Brazil

ABSTRACT || Objectives: the objective of this study was to assess the knowledge and attitude of dentists towards the dental treatment of renal transplant patients through questionnaires. Methods: a total of 416 dentists were interviewed and responded 10 multiple-choice questions. Results: most participants $(214 / 416 ; 51.4 \%)$ felt uncomfortable extracting teeth in renal transplant patients. The great majority $(354 / 416,85 \%)$ would prescribe prophylactic antibiotics before simple dental extraction, whereas $43 \%$ would prescribe antibiotics, even before non-invasive procedures. Conclusions: our data showed that the interviewed dentists are unfamiliar with the management of renal transplant patients and most of them would prescribe prophylactic antibiotics inappropriately, despite the inexistence of scientific evidence supporting this practice.

DESCRIPTORS | Dental Care; Kidney Transplantation; Antibiotic Prophylaxis; Immunocompromised Host; Antibiotics.

RESUMO | Conhecimentos e atitudes de dentistas sobre o tratamento de pacientes de transplante renal - Objetivos: o objetivo deste estudo foi avaliar os conhecimentos e as atitudes de dentistas sobre tratamento odontológico de pacientes de transplantes renais, por meio de questionários. Métodos: ao todo, 416 dentistas foram entrevistados e responderam 10 questões de múltipla escolha. Resultados: a maioria dos participantes $(214 / 416 ; 51.4 \%)$ se sentiu desconfortável na extração de dentes em pacientes com transplantes renais. A grande maioria $(354 / 416,85 \%)$ prescreveria antibioticoterapia profilática antes de uma exodontia simples, enquanto $43 \%$ prescreveriam antibióticos, mesmo antes de procedimentos não invasivos. Conclusões: nossos dados mostraram que os dentistas entrevistados não estão familiarizados com o manejo de pacientes de transplante renal, sendo que a maioria prescreveria antibióticos profiláticos erroneamente, apesar da inexistência de evidências científicas embasando tal prática. 


\section{INTRODUCTION}

Renal transplantation is a treatment chosen for terminal chronic renal failure. United States is the first and Brazil is the second leading country in the world in absolute number of renal transplantations. In Brazil, in 2016, 5,492 renal transplants were performed. ${ }^{1,2}$

Nowadays, the success rate of renal transplantations is caused, particularly, by the development of efficient immunosuppressive drugs and the improvement of surgical techniques, which extends the recipient's life expectancy. Given the increase in longevity, it is expected that transplanted people will need and seek dental treatment during their lives. The need for the use of immunosuppressive drugs, in association with a variety of co-morbidities, makes renal transplant patients a unique group of patients with special oral healthcare needs. ${ }^{3,4}$

Although the first renal transplantation in the world was performed in 1933, even today there are a few guidelines based on robust scientific evidence guiding dentists on the dental management of renal transplant patients, especially regarding the risk of infection from dental procedures. Concerned with this situation, Guggenheimer et al. ${ }^{5}$ applied a questionnaire to 294 representatives of organ transplantation centers in the USA to know the guidelines and recommendations they were providing to dentists about transplanted patients. The results showed the lack of standardized recommendations. The majority of the organ transplantation centers (77\%) recommended antibiotic prophylaxis for transplanted patients prior to any invasive or non-invasive dental procedure. Six percent of these centers recommended the prescription of prophylactic antibiotics only before invasive dental procedures. ${ }^{5}$

A similar study was conducted in Germany by Ziebolz et al. ${ }^{6}$ showing that there was no uniformity in the recommendations given to dentists regarding antibiotic prescription before invasive dental procedures. From the 50 organ transplantation centers in Germany, 83\% recommended prophylactic antibiotic therapy for dental procedures. There was also no consensus on which dental procedures should be preceded by this therapy. ${ }^{6}$

Prior to these studies, Palmer at al. ${ }^{7}$ were already concerned with the indiscriminate use of prophylactic antibiotics in medically compromised patients for dental procedures. Those authors analyzed the answers from 929 dentists in the United Kingdom and found that more than $40 \%$ of the respondents prescribed prophylactic antibiotics for patients with medical diseases and conditions, including renal transplant patients undergoing minor oral surgeries to prevent post-operative infection. The study found that a significant number of dentists prescribed prophylactic antibiotics inappropriately for dental procedures and medical conditions to which there is little or no evidence of their need. Those authors also suggested the need to elaborate guidelines for dentists on the prophylactic use of antibiotics.?

We have found no studies investigating the attitude of Brazilian dentists regarding the dental treatment and clinical management of renal transplant patients.

Our objective is to know the attitude of Brazilian dentists towards dental procedures in renal transplant patients through a questionnaire. Specifically, we have sought to identify how dentists feel about treating renal transplant individuals, whether they prescribe prophylactic antibiotics or not, and in positive cases, which dental procedures led them to make this prescription and which therapeutic scheme was chosen.

Our hypothesis is that, similarly to other countries, many Brazilian dentists prescribe prophylactic antibiotics before routine dental procedures, such as minor oral surgeries, for renal transplant patients in the stable phase of the disease 
despite the lack of scientific evidence supporting this practice.

\section{MATERIAL AND METHODS}

This cross-sectional research was designed to assess the knowledge and attitude of dentists regarding the treatment of renal transplant patients through a questionnaire designed by the authors of the study. After approval by the Research Ethics Committee of the School of Dentistry of the University of São Paulo (no: 56834816.9.0000.0075), the same interviewer applied the questionnaire to dentists attending a large General Dental Congress in Brazil, held in the state of São Paulo, Brazil.

The questionnaire consisted of 14 questions divided into 2 sections: the first section containing 4 demographic items; and the second including 10 multiple-choice questions on their knowledge and attitudes. These questions sought to assess the attitudes, knowledge and confidence of the dentists regarding the treatment of renal transplant patients. The demographic questions included age, sex, years of practice and specialty. Four hundred sixty-five dentists were approached, 43 refused to answer the survey and 6 questionnaires were excluded because they were partially filled. Thus, 416 questionnaires were considered valid. Only subjects who signed the informed consent form were included in the study.

For the most part, the statistical analysis comprised descriptive statistics and the chi-square test $\left(\mathrm{x}^{2}\right)$ was performed with the significance level at $5 \%$. Data were entered into the Statistical Package for the Social Sciences program (SPSS, version 18.0 IBM, Chicago, IL, USA) for analyses.

\section{RESULTS}

A total of 416 dentists were interviewed, from whom 78 (18.8\%) were men and 338 (81.2\%) women. Mean age was 31 years old, with 182 interviewees aged from 20 to 29 years old (43.7\%), 134 aged from 30 to 39 years old (32.2\%), 63 aged from 40 to 49 years old (15.1\%) and 37 older than 50 years old (9.0\%). Most interviewees ( $\mathrm{n}=197,47.4 \%)$ graduated 5 years earlier or less, $122(29.2 \%)$ graduated 6-15 years earlier and 97 (23.4\%) graduated 16 years earlier or more. In total, 245 (58.9\%) dentists reported that they had some specialty acknowledged by the Federal Dentistry Council and 65 (15.6\%) had a stricto sensu graduate degree (Master's or Doctorate degree). Table 1 summarizes demographic data.

Table 1 | Demographic data

\begin{tabular}{c|c} 
Sex & $\mathrm{N}(\%)$ \\
Men & $78(18.8)$ \\
\hline Women & $338(81.2)$ \\
\hline Age $[$ mean(SD)] & $31(9.6)$ \\
\hline $20-29$ & $182(43.7)$ \\
\hline $30-39$ & $134(32.2)$ \\
\hline $40-49$ & $63(15.1)$ \\
\hline More than 50 & $37(9.0)$ \\
\hline Time since graduation & N $(\%)$ \\
\hline 5 years or less & $197(47.4)$ \\
\hline 15 $-152(29.2)$ \\
\hline 16 years or more & $122(23.4)$ \\
\hline Graduate degree & $\mathrm{N}(\%)$ \\
\hline Specialty & $245(58.9)$ \\
\hline Stricto sensu & $65(15.6)$ \\
\hline \hline
\end{tabular}

*Specialty acknowledged by the Federal Dentistry Council;

Master's or doctorate degree.

In Question number 2, most interviewees ( $\mathrm{n}=251$, $60.3 \%$ ) reported that they felt "very comfortable" or "comfortable" treating renal transplant patients, especially if non-invasive procedures were involved (Table 2). Most respondents, 223 (53.6\%), requested some complementary examination, such as complete blood test and coagulogram, prior to the treatment (Question 3), and 134 (32.2\%) interviewees prescribed amoxicillin $2 \mathrm{~g}$ as prophylactic therapy 1 hour prior to the non-invasive dental procedure (Question 5). In Question 6, more than the half of the participants $(214 / 416,51.4 \%)$ reported that they felt "very uncomfortable" or "uncomfortable" 
performing tooth extraction in renal transplant patients. A great majority (358, 86.1\%) would request authorization from the transplant physician for this invasive procedure (Question 8) and, in Question 9, $84.8 \%$ would prescribe prophylactic antibiotics before performing the procedure. In Question 10, the dentists were asked if they have ever treated a renal transplanted patient before, 82 (19.7\%) responded "yes". Table 2 lists the questions asked to the dentists and their answers.

Table 2 | Questionnaire applied to dentists and answers given:

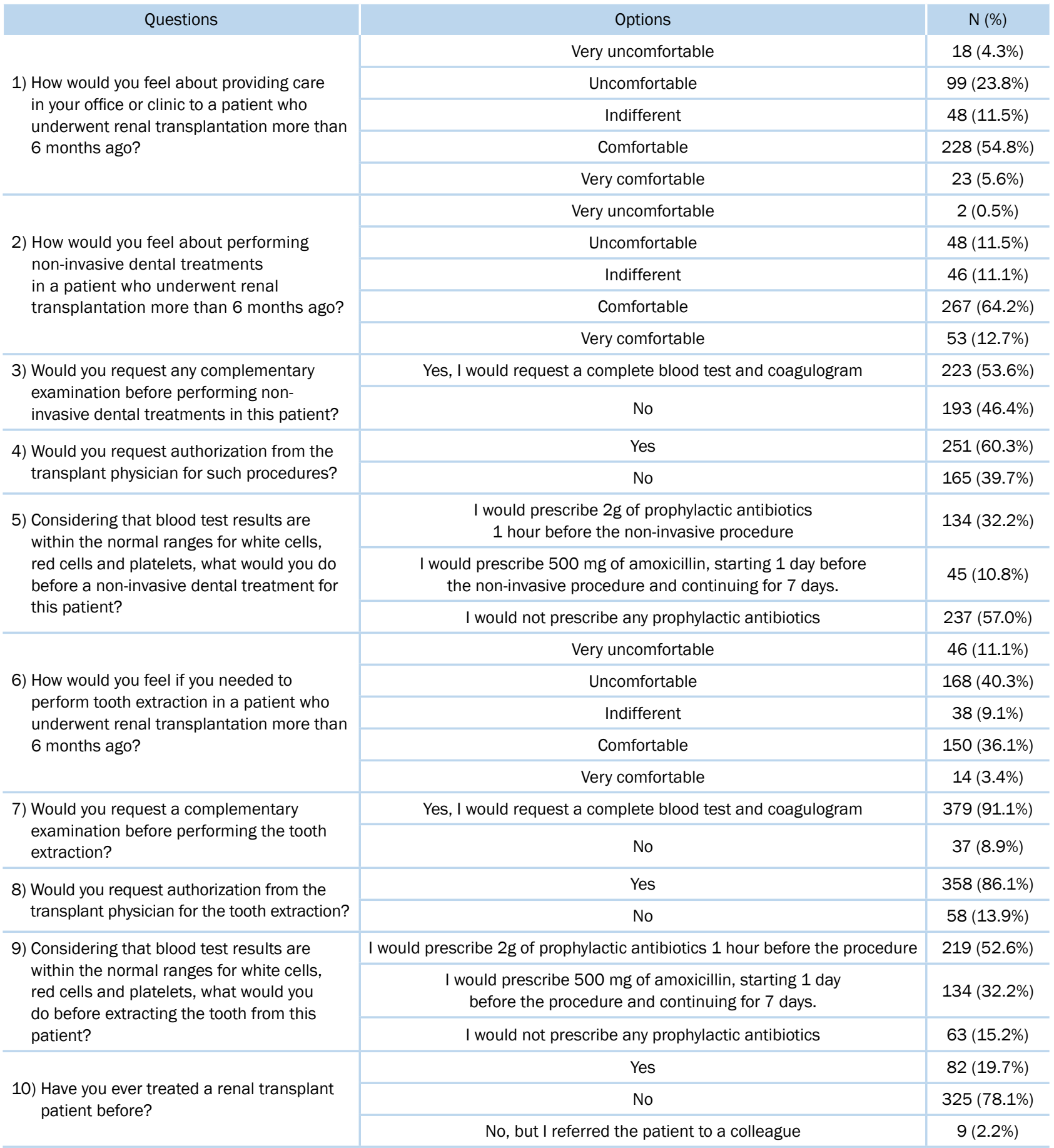


In Question 5, even considering that blood tests results were within the normal ranges for red and white cells, 179 dentists (43\%) would prescribe antibiotic prophylaxis before non-invasive dental treatment and 353 dentists (84.8\%) would prescribe antibiotic prophylaxis before an invasive procedure (Question 9).

There was no association between time since graduation and use of antibiotic prophylaxis before extracting a tooth in a renal transplant patient, even with normal blood tests results ( $\mathrm{x}^{2}$ test; $\mathrm{p}=0.983$ ).

\section{DISCUSSION}

Our results have shown that most respondents feel confident to perform non-invasive dental procedures in renal transplant patients. Many dentists (i.e., $43 \%$ of the interviewees) reported that they would prescribe prophylactic antibiotics for stable renal transplant patients, including in cases of non-invasive dental procedures such as restorations, impression and prophylaxis. This result is concerning because non-invasive dental procedures do not imply any risk of infection, even in individuals with some degree or type of immunosuppression, thus meaning that antibiotic prophylactic therapy is not indicated prior to these procedures. ${ }^{8}$ Considering that the transient bacteremia resulting from many of these procedures is similar to that caused by daily tooth-brushing, for example, the prescription of prophylactic antibiotics in these situations is not scientifically supported. Moreover, this attitude would only contribute to the development of bacterial resistance and place the patient at risk of secondary side-effects (e.g. allergic reactions), including unnecessary costs. ${ }^{9}$

A considerable proportion of the participating dentists (84.8\%) would prescribe prophylactic antibiotics for renal transplant patients undergoing a minor oral surgery, such as single tooth extractions. Scientific evidence shows that healthy individuals present a low rate of post-extraction infection and that antibiotic medications have little effect on the reduction of these complications. ${ }^{9}$ Additionally, we must consider the concept that antibiotics should never replace good surgical techniques and aseptic conditions. ${ }^{10}$ Disregard for this evidence and lack of knowledge on the immune regulation induced by immunosuppressive drugs necessary after kidney transplantation, contribute to the high prevalence of inadequate prescriptions of prophylactic antibiotics in stable renal transplant patients. Bacteremia is common after invasive dental procedures and when bacteria enter the blood circulation, some have the potential to cause distant-site infections, like endocarditis and prosthetic joint infection. ${ }^{9}$ However, these risks are considered for individuals with congenital heart defects or with a prosthetic joint. There is no scientific evidence showing that the use of antibiotic drugs before dental procedures in renal transplant patients is beneficial to them. ${ }^{9}$

Lockhart et al. ${ }^{11}$ performed a systematic review and concluded that there are a few prospective scientific studies demonstrating that the risk of invasive dental procedures would lead to systemic complications in immunosuppressed transplant patients. The authors ranked the degree of scientific evidence on the use of prophylactic antibiotics into categories IIB and IIC, i.e., they reported low scientific evidence based on experts' opinions. ${ }^{11}$

Conversely, there is already some evidence that stable renal transplant patients, who use immunosuppressive drugs on a continuous basis, exhibit a post-operative healing process similar to that of immunocompetent individuals after a tooth extraction. ${ }^{12}$ This observation corroborates with the current objective of maintaining immunosuppressive therapy, which is to offer the transplant patient an immunosuppressive dose as low as possible to prevent rejection of the organ while decreasing the risk of infection to the host. We must emphasize that, according to the literature, lymphopenia is the most common immunological change in renal transplant 
patients immunosuppressed by medications. Neutropenia may affect about $30 \%$ of the renal transplant patients, occurring approximately 80 days following the transplantation. Considering that neutrophils are crucial cells for antibacterial defense, patients with counts below 1000 cells/ml are more susceptible to bacterial infection. In this case, the prescription of prophylactic antibiotics is mandatory for invasive procedures. Although neutropenia is not a common complication after six months of transplantation, requesting a blood test before tooth extraction in these patients is important. ${ }^{13}$

Recommendations for the use of antibiotic prophylactic before dental treatment should be based on the risks and benefits. The financial cost of prophylactic antibacterial therapy is acceptable when compared to the total cost of the dental treatment. The benefit would involve the prevention of infectious complications secondary to dental procedures. Finally, the risk of antibiotic prophylaxis is the occurrence of adverse reactions, especially allergic ones, and selection of resistant strains. ${ }^{14}$

Amoxicillin is the antimicrobial medication most frequently prescribed for these procedures, which was corroborated by our participants. This is a logical choice as serum levels reach high concentrations, being effective against facultative and anaerobic microorganisms that can cause postoperative infections in the oral cavity. ${ }^{15}$ However, our results showed that many dentists follow the antibiotic posology intuitively, an attitude that is not endorsed by the American Heart Association, and therefore, with no scientific support regarding its effectiveness against infections. Other studies have already demonstrated that the dentists' knowledge of prophylactic antibiotic therapy is poor and worrying, and our results certainly corroborate this fact. ${ }^{16}$

The prescription of antibiotic prophylaxis prior to dental procedures is systemically used compromised patients, despite the inexistence of scientific evidence to support this practice. This misuse of antibiotic prophylaxis put these patients at risk of drug exposure. The goal of antibiotic prophylaxis is to prevent a local wound or systemic infection that could arise from a transient bacteremia caused by dental procedures. More than 700 bacterial species exist in the oral cavity, some of them enter the bloodstream through daily routine activities, such as tooth brushing, chewing or invasive dental procedures. ${ }^{17}$ The intensity of bacteremia changes depending on the procedure. Less invasive dental procedures, such as the extraction of deciduous tooth, restorations and dental impressions, produce transient bacteremia similar to that produced by the activities mentioned above. Therefore, the use of antibiotic prophylaxis before these procedures is not indicated in patients with a solid organ transplant. ${ }^{11}$

Regarding dental extractions, subgingival scaling and other invasive procedures, there is no evidence supporting the idea that solid organ transplant patients are at a high risk of infections caused by dental procedures during the stable phase, which usually occurs when a balance in the immunosuppression therapy is achieved. ${ }^{11,18,19}$

Since solid organ transplant recipients have immunosuppression induced by drugs, the objective of this therapy is to achieve sufficient immunosuppression to avoid organ rejection without making the host susceptible to infections.

The lack of scientific evidence supporting or refuting the use of antibiotic prophylaxis in most situations related to the host must be carefully evaluated by the dentist. The clinical criteria for assessing the patient's general health, analysis of hemogram results, local conditions and magnitude of dental procedures must be considered and confronted with the risks of adverse effects of antibiotics. If the dentist decides that preventing an infection overweighs these risks, the American Heart Association's prescription (amoxicillin $2 \mathrm{~g}$ before the procedure) should be considered. ${ }^{20}$ The most important antibiotic dose is the pre-operative. 
There is no scientific evidence supporting the use of antibiotic prophylaxis after an invasive procedure, except for long cardiac surgeries and orthopedic surgeries for the implantation of prosthesis. In these cases, maintaining the antibiotic administration for up to 48 hours after the surgery is acceptable. ${ }^{20}$ Finally, the dentist must consider that immediate post-operative follow-up is essential to detect and treat infections, especially in systemically compromised patients.

\section{CONCLUSION}

Our results show evidence that dentists, in general, feel insecure to perform dental treatment on renal transplant patients as these practitioners prescribe prophylactic antibiotics excessively and based on therapeutic posology with no scientifically proven effectiveness.

Knowing the patient's medical history and communicating with the transplant physician is important and necessary, however, providing dentists with clear guidelines based on scientific evidence for the prophylactic prescription of antibiotics is necessary to decrease the exaggerated and inappropriate use of these medications.

The knowledge about the physiopathology of some usual systemic conditions presented nowadays, like non-communicable chronic diseases, have to be focused and improved to Brazilian undergraduate dentistry students, given the high frequency of these diseases in Brazil.

Conflicts of interest: none.

Financial support: Fundação de Amparo à Pesquisa do Estado de São Paulo - FAPESP. Project: 2017/07778-8.

\section{REFERENCES}

1. Sociedade Brasileira de Nefrologia (BR). O que é transplante renal? [Internet]. São Paulo, SP: Author; 2017 [updated 2012 Sep 16; cited 2017 Oct 1]. Available from: https://sbn.org.br/ publico/tratatamentos/transplante-renal/.
2. Associação Brasileira de Transplante de Órgãos (BR). Direcionamento dos transplantes do Brasil e em cada estado (2009-2016) [Internet]. São Paulo, SP: Author; 2017 [cited 2017 Oct 1]. Available from: http://www.abto.org.br/abtovo3/ Upload/file/RBT/2016/RBT2016-leitura.pdf.

3. Hurst P. Dental issues before and after organ transplantation: organ transplantation. Austin, TX: Landes Bioscience; 2000.

4. Little JW, Falace DA, Miller CS, Rhodus NL. Little and falace's dental management of the medically compromised patient. 8th ed. St. Louis, MO: Elsevier; 2013.

5. Guggenheimer J, Mayher D, Eghtesad B. A survey of dental care protocols among US organ transplant centers. Clin Transplant. 2005;19(1):15-8.

6. Ziebolz D, Hraský V, Goralczyk A, Hornecker E, Obed A, Mausberg RF. Dental care and oral health in solid organ transplant recipients: a single center cross-sectional study and survey of German transplant centers. Transpl Int. 2011;24(12):1179-88.

7. Palmer NA, Pealing R, Ireland RS, Martin MV. A study of prophylactic antibiotic prescribing in National Health Service general dental pratice in England. Br Dent J. 2000;189(1):43-6.

8. Gutiérrez JL, Bagán JV, Bascones A, Llamas R, Llena J, Morales A, et al. Consensus document on the use of antibiotic prophylaxis in dental surgery and procedures. Med Oral Patol Oral Cir Bucal. 2006;11(2):e188-205.

9. Mougeout FKB, Saunders SE, Brennan MT, Lockhart PB. Associations between bacteremia from oral sources and distant-site infections: tooth brushing versus single tooth extraction. Oral Surg Oral Med Oral Pathol Oral Radiol. 2015;119(4):430-35.

10. Longman LP, Martin MV. The use of antibiotics in the prevention of postoperative infection: a re-appraisal. Br Dent J. 1991;170(7):257-62.

11. Lockhart PB, Loven B, Brennan MT, Fox PC. The evidence base for the efficacy of antibiotic prophylaxis in dental practice. J Am Dent Assoc. 2007;138(4):458-74; quiz 534-5, 437.

12. Guilheiro JM, Sá SNC, Caliento R, Gallottini MHC. Estudo retrospectivo sobre os cuidados odontológicos em pacientes transplantados renais. Proceedings of the $32 n d$ SBPqO Annual Meeting. Braz Oral Res. 2015;29(Suppl 1):515.

13. Mavrakanas TA, Fournier MA, Clairoux S, Amiel JA, Tremblay ME, Vinh DC, et al. Neutropenia in kidney and liver transplant recipients: risk factors and outcomes. Clin Transplant. 2017;31(10):e13058. 
14. Lodi G, Figini L, Sardella A, Carrassi A, Del Fabbro M, Furness S. Antibiotics to prevent complications following tooth extractions. Cochrane Database Syst Rev. 2012;11:CDoo3811.

15. Gill Y, Scully C. Orofacial odontogenic infections: review of microbiology and current treatment. Oral Surg Oral Med Oral Pathol. 1990;70(2):155-8.

16. Lisboa SM, Martins MA, Castilho LS, Souza e Silva ME, Abreu MH. Prescribing errors in antibiotic prophylaxis by dentists in a large Brazilian city. Am J Infect Control. 2015;43(7):767-8.

17. Alao U, Pydisetty R, Sandiford NA. Antibiotic prophylaxis during dental procedures in patients with in situ lower limb prosthetic joints. Eur J Orthop Surg Traumatol. 2015;25(2):217-20.

18. Lockhart PB, Brennan MT, Fox PC, Norton HJ, Jernigan DB, Strausbaugh LJ. Decision-making on the use of anti- microbial prophylaxis for dental procedures: a survey of infectious disease consultants and review. Clin Infect Dis. 2002;34(12):1621-6.

19. Napeñas JJ, Kujan O, Arduino PG, Sukumar S, Galvin S, Baričević M, et al. World Workshop on Oral Medicine VI: controversies regarding dental management of medically complex patients: assessment of current recommendations. Oral Surg Oral Med Oral Pathol Oral Radiol. 2015;120(2):207-26. 20. Wilson W, Taubert KA, Gewitz M, Lockhart PB, Baddour LM, Levison M, et al. Prevention of infective endocarditis: guidelines from the American Heart Association Rheumatic Fever, Endocarditis, and Kawasaki Disease Committee, Council on Cardiovascular Disease in the Young, and the Council on Clinical Cardiology, Council on Cardiovascular Surgery and Anesthesia, and the Quality of Care and Outcomes Research Interdisciplinary Working Group. Circulation. 2007;116(15):1736-54. 